\title{
Modelling Radioactive Materials Tracking in Sea Transportation by RFID Technology
}

\author{
S. Bauk \\ Durban University of Technology, Durban, South Africa
}

\begin{abstract}
The demand for radioactive materials has been increasing over the past decades, and therefore it is to be expected that the need for radioactive cargo transportation shall also increase. The Radio Frequency and Identification (RFID) technology has become the most spread for tracking and tracing radioactive cargo in road and rail transportation. The easy installation, simple and fast data transfer from the sensors through RFID readers have provided a safe and easy way of using this technology. A variety of sensors, such as seal, temperature, humidity, shock, gamma radiation and neutron detector are the key, but not the only ones of the complex system that is responsible for the safe transportation of radioactive cargo. By the appropriate software, on-site databases and secured Internet, the operator has insight into the condition of the radioactive material inside the containers without the risk of exposure to radiation, and without compromising the safety and security of the data exchange at any time. Thanks to the latest-generation crypto tools, security is additionally guaranteed. Within the context, this article presents a model of radioactive cargo tracking by RFID technology in sea transportation. The model is based on the ARG-US RFID system successfully deployed in road and rail transportation and its possible implementation at ships specialized for nuclear cargo transport.
\end{abstract}

\section{INTRODUCTION}

Growing society's energy needs cause the development and utilization of nuclear power in combination with nuclear fuel recycling. Nuclear energy is very important in the sectors of industry, agriculture and medicine. Countries with nuclear reactors need to transport radioactive materials to reprocessing plants prior of storage of residuals. Therefore, it is reasonable to expect that sea transportation of radioactive materials will be increasingly involved. Coastal countries, including maritime industry in general, have to provide transportation of radioactive materials that include irradiated nuclear fuel, plutonium and high-level radioactive wastes by ships in safe, reliable and secure manner.
Today nuclear power provides approximately $10 \%$ of the world's electricity. Due to the clime change, $80 \%$ of all electricity will need to be clean and low carbon by 2050 . Therefore, nuclear capacity should be considerably increased to meet climate goals. Russia, India and China are currently leaders in expanding nuclear power production. For instance, China has now nine reactors under construction. Finland, United Arab Emirates, Belarus, Bangladesh and Turkey are also building new reactors. Currently, in total 450 nuclear power reactors operate worldwide [11].

However, nuclear power is a controversial energy source. Plans for increasing nuclear capacity are always connected with huge and high risk investments. The Londonderry (Pennsylvania) in 
1979, Chernobyl (Ukraine) in 1986 and Fukushima (Japan) in 2011 accidents have raised serious safety concerns. Consequently, several countries moved away from nuclear power, citing safety risks and financial costs.

Small modular reactors as an alternative solution allow combining nuclear power with renewables, i.e., sources of energy that are not depleted by use, such as water, wind, solar power, etc. The environmental consciousness is generally rising and it becomes evident that energy needs could not be satisfied in the future by sole use of coal or natural gas. Besides for producing electrical power, nuclear energy is used for variety of research, industry, agriculture, and medicine purposes.

With increase of nuclear capacity worldwide, it is to be expected that the need for massive radioactive materials (RAM) transportation will increase. Thereby, sea transportation shall undoubtedly play an important role in satisfying requirements for irradiated nuclear fuel, plutonium and radioactive waste [27].

In this article, we focused on literature review in the field of RAM transportation by means of sea, road and rail transport (Section 2). An overview of the ARG-US project achievements, when it comes to tracking and tracing RAM in road and rail transportation, is presented (Section 3). Then, an attempt to conceive a similar model of RAM tracking in sea transportation is presented at high level of abstraction (Section 4). Finally, conclusion and some directions for further investigation in this domain are given (Section 5).

\section{SECONDARY LITERATURE SOURCES}

There is a scarcity of research studies on nuclear cargo transportation available online. Below are shortly presented some of the articles, which have been found after an extensive web search.

Legislative framework of maritime transportation of irradiated nuclear fuel (INF), plutonium and radioactive wastes together with widely expressed concern that an accident may occur to a ship carrying such cargo has been studied in [27]. The same study reviews the legal issues associated with the right of emergency access to a foreign seaport by a ship transporting nuclear materials. It also considers whether seabed characteristics should be assessed in determining the routing of such ships, bearing in mind that ocean floor topography and seawater depth will be crucial in determining whether recovery of nuclear materials would be practicable in the event of ship sinking.

The description of ship carrying nuclear cargo construction requirements has been given in [5]. This paper presents INF Code requirements due to the ship's construction, fire safety measures, electrical power supply, cargo stowage and segregation, emergency planning and security measures.

World Nuclear Transport Institute (WNTI) has published a fact sheet on the transport of nuclear fuel [28]. This study gives relevant data on the nuclear fuel cycle, front-end operations, fuel fabrication, reprocessing, transport packaging, sea transport, purpose-built vessels, etc.

A model of radioactive transportation accident response in Japan has been presented in [26]. The authors have given an overview of the tracking system for radioactive material transport including sensor unit, communication network, central monitoring center and sub-terminals, which provide trend viewer, abnormal situation detection support system, current situation and next step during the shipment.

The authors of the references $[6 ; 7 ; 25]$ have given description of applying RFID technology in nuclear material-cargo management. They have provided prototype tag design and production, prototype application software including graphical user interface and preliminary test results in terms of read range, sensor performance, memory read/write, seal sensor, battery life, etc. It is worth to mention that reference [23] gives a general insight in RFID technology and its applications.

The authors of the reference [18] have dealt with mathematical modeling and simulations, based on special tran function theory (STFT), in estimating temperature of plutonium in transportation.

The authors of [14] have investigated efficiency of detectors for intercepting illicit trafficking of fissionable material in container cargo in maritime transportation. They have suggested tagged neutron inspection system in addition to container content $X$ ray scan, etc.

\section{TRACKING RADIOACTIVE MATERIALS IN ROAD AND RAIL TRANSPORTATION}

In 2008 Argonne National Laboratory (Chicago, Illinois, USA) Packaging Certification Program (PCP) team has developed RFID tracking and monitoring system for the management of RAM packages during storage and transportation [24]. This system, called ARG-US, is composed of appropriate hardware modification, application software, secured database, protected web access, and irradiation experimental measurements. The B fissile material drums (models 9975, 9979 and ES-3100) certified by US Department of Energy and US Nuclear Regulatory Commission have been used for testing the prototype. The demonstration of the system successfully integrated Global Positioning System (GPS) for vehicles and railway wagons positioning, including their RAM cargo, satellite and cellular General Radio Package Service (GPRS) wireless communications, the RFID tags attached to the RAM drums, and Geographic Information System (GIS) technology in geo-fencing purposes [17], etc. The RFID tags and GPS technology in combination with GIS enable dedicated software to trigger a response when a mobile device enters or leaves certain geographical area. The RFID in combination with GPS generate an alarm in the case of an incident with the RAM drums. An ARG-US sensor' unit sealed at each RAM drum is presented in Figure 1. The ARG-US tags enable sophisticated sensing, monitoring and communication capabilities 
directly from the packages-drams. These customizable tags with integrated communications platform for tracking and monitoring nuclear materials in real time are designed to protect facilities and population in comprehensive and cost-effective way [2].

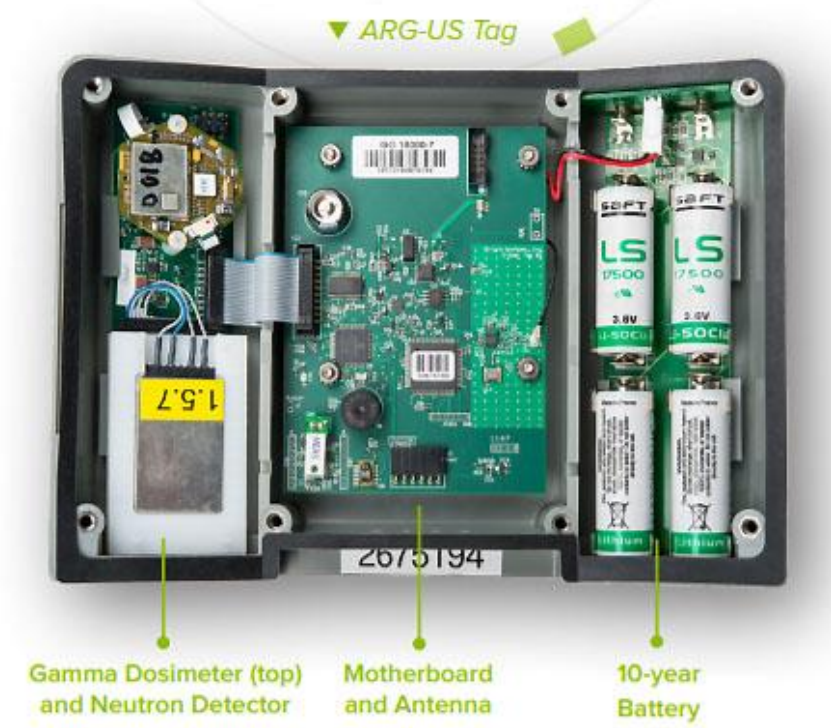

Figure 1. ARG-US sensors' unit sealed at each RAM drum (Source: [1])

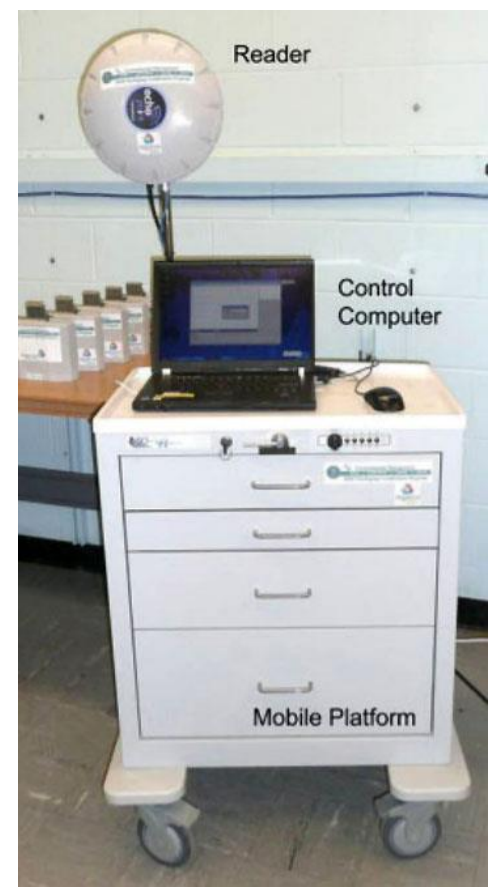

Figure 2. A stand-alone RFID temperature monitoring system on mobile platform (Source: [16])

The ARG-US RFID system consists of tags (transponders), readers (interrogators) and application software. The tag, with a built-in temperature sensor, is attached to the exterior of the package using flange bolts. The application software enables remote reading, via radio waves, of the sensor temperature. The system monitors temperature continuously, records the data periodically and reports off-normal conditions instantly. The temperature data and event histories are stored in the tag's internal memory, as well as in the control computer to which the reader is connected (Figure 2). In a large installation, the system may be linked to a server and accessible via secured Internet.

The first experiment with ARG-US system has been made with road transportation of a vehicle with 14 RAM drums along the route Chicago (Illinois) to Augusta (South Carolina). Sensor data were updated every 10 minutes, while several incidents of seal (i.e., loosening the drum bolts) and shock sensor violations were observed. At two mountain spots lost of satellite/cellular connection has been noticed. In addition, an incident with low battery level at sensors' unit attached to the RAM drum has been indicated (Figure 3).

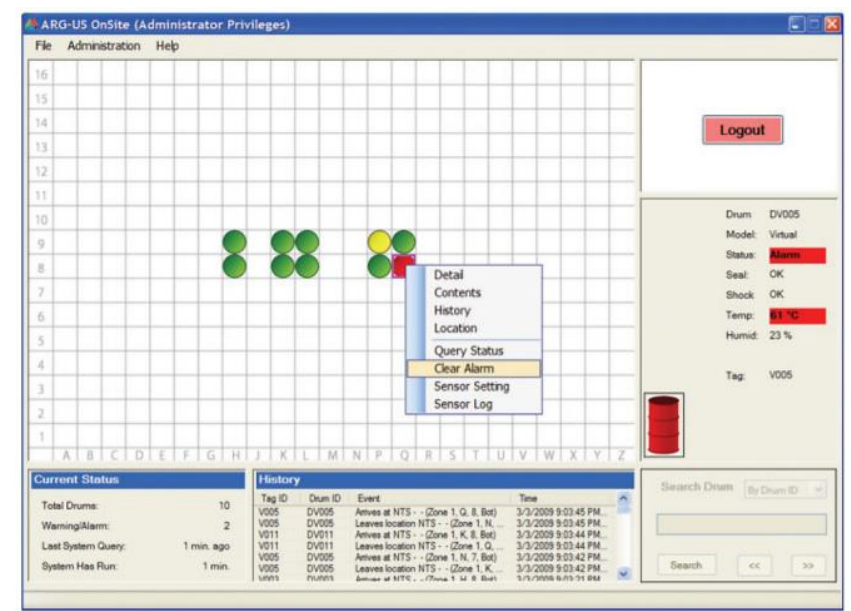

Figure 3. The ARG-US graphical interface: round symbols represent RAM drums (Source: [9])

The RAM dram marked yellow indicates a potential danger since battery is low at the moment. A drum marked red means serious danger and instigates an alarm, while drums marked green indicate that everything is in order and there is no danger of an incident. The system tracks the drums in road transportation in close to real time.

After this experiment in road transportation of RAM cargo, a series of experiments at Argonne (Chicago, Illinois, USA) radiological facility has been realized across the RAM drums storage areas. Two layers of network for tracking and tracing stored RAM drums have been set: a multi-sand wired one as the first layer based on Ethernet, and the second one based on wireless network. Blink sensors have been used to communicate only upstream with the Remote Area Modular Monitoring (RAMM) infrastructure nodes. They enable fast connection to the existing wireless sensor network. A digital video camera, or optical sensor, has been also incorporated into the RAMM platform. More about these second term set of the ARG-US experiments can be found in references [8;15;17]. There is no technology, besides ARG-US, which can track, monitor, report, communicate and enable rapid response to potential emergencies related to nuclear wastes in storage and transportation [2]. This system has contemporary design and flexibility. It demonstrated high performances and it is commercially available.

Due to the lack of research articles when it comes to tracking RAM drums at the level of single items in sea transportation, we have used the experiences 
from the ARG-US project realization to conceive and propose a model for RAM cargo tracking in sea transportation. Prior to the presenting this model, a short overview of some technical-structural requirements that ships for transportation of nuclear cargo have to comply with, in order to ensure safe RAM transportation, is given.

\section{SEA TRANSPORTATION OF RADIOACTIVE MATERIALS}

The main sea trade routes of nuclear material are between Japan, UK and France, including routes targeting Russia, Sweden, Canada, Argentina, Brazil, Chile, Ireland, South Africa, etc. Legislative framework for coastal states regarding sea transportation of irradiated nuclear fuel, plutonium and radioactive wastes correspond to the International Convention for the Safety of Life at Sea (SOLAS), the International Maritime Dangerous Goods (IMDG) Code, the United Nations Convention for the Law of the Sea (UNCLOS), the Irradiated Nuclear Fuel Code (INFC), etc. The International Maritime Organization (IMO) sub-committee of Safety of Navigation (NAV) regulations cover the route planning, notification and consultation with coastal states, including possible restrictions and exclusion of certain routes. Aids, equipment and devices that would facilitate location and salvage of a ship and/or nuclear cargo in the case of emergency are covered by IMO sub-committees on Carriage of Dangerous Goods (CDG) and radio Communications (COM) including both terrestrial and satellite channels [2].

The world's most experienced shipper of nuclear materials is Pacific Nuclear Transport Limited (PNTL). The homeport of this company is Barrow-inFurness in England (UK). The company has successfully completed 180 shipments during the last 40 years. The PNTL have safely sailed over five million miles. This is the equivalent of going to the Moon and back over ten times. More than 2000 casks (drums) of nuclear material have been safely transported by PNTL since its establishment. The company has the most experienced nuclear transport crew in the world. On average, each crewmember has more than twenty years of experience with PNTL. Today, three PNTL ships are in service: Pacific Heron, Pacific Egret and Pacific Grebe. These vessels are capable of carrying spent fuel, mixed oxide fuel (MOX) fuel assemblies and vitrified high-level waste [19-22]. The process of cask with nuclear material unloading in a PNLT ship is shown in Figure 4.

The PNTL ships have double hull construction, dual navigation monitoring and calling systems, twin engines, rudders and propellers, backup power generators, radioactivity monitoring, secured cargo, enhanced buoyancy, bow thrusters, backup generators, additional firefighting equipment and weather routing system. It is important to emphasize that during the past forty years and numerous PNTL ships voyages, there has never been a single incident resulting in the release of radioactivity. Security is a top priority for ships carrying nuclear materials. Shipments must comply with coastal state requirements, as well as physical protection measures developed by the International Atomic Energy Agency (IAEA) and IMO.

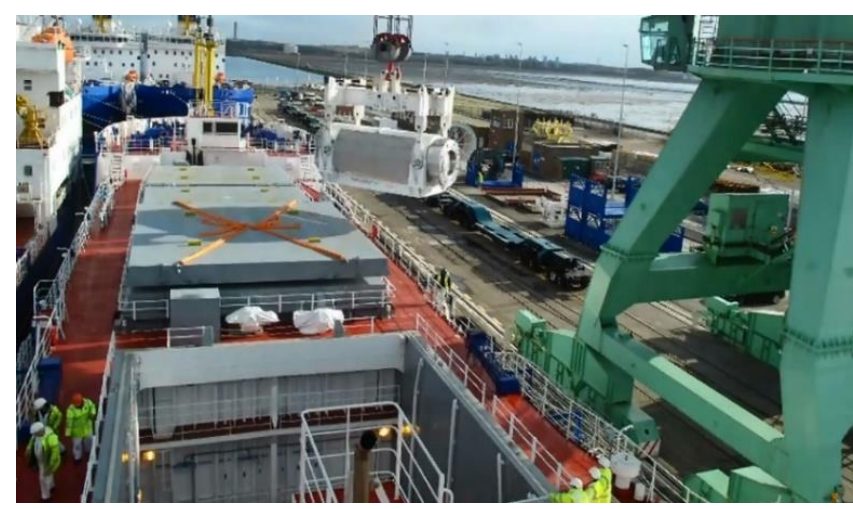

Figure 4. Unloading cask with nuclear cargo from PNTL ship's hull (Source: [19])

\subsection{Model of radioactive materials tracking}

Since in the focus of this paper is tracking and tracking RAM via RFID in sea transportation, the attempts towards compiling results and experiences from ARG-US and similar projects and proposing a framework of an appropriate info-communication model (Figure 5) have been done [4]. As reference are used previously presented PNTL ships.

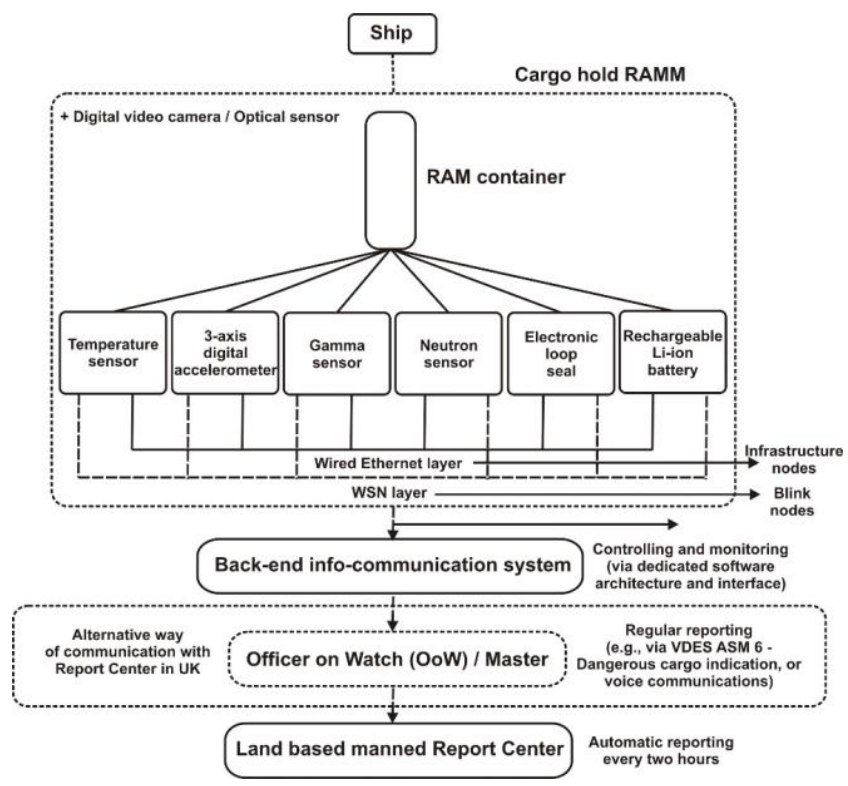

Figure 5. Model of a nuclear cargo ship's communication scheme with manned Report Center (Source: [4])

All PNTL ships have satellite navigation and weather routing equipment, as well as tracking equipment. These systems enable PNTL ships to follow the safest route and avoid severe weather conditions. Ship's position is monitored at any stage of her voyage. This voyage monitoring system automatically reports the vessel's latitude and longitude, speed and heading every two hours. If the report center does not receive message within a predetermined time, PNTL's emergency response system is automatically activated [20]. If a ship accounts 
difficulty, trained and fully equipped PNTL emergency team is 24 hours on stand by to offer assistance. All emergency arrangements are in accordance to IAEA regulations [21]. Special monitors in the holds of each PNTL ship would provide information about the status of the cargo to a salvage team.

By the proposed model is assumed that each ship's cargo hold is treated as a Remote Area Modular Monitoring (RAMM) sub-system connected with central monitoring system on board refereeing to AGR-US project attainments [6;7;8;15;17;25]. A digital video camera or optical sensor might be incorporated into each RAMM (RAM cargo hold). The RFID active tags attached to each RAM drum's bolt contains following sensors: temperature, 3-axis digital accelerometer, gamma sensor, neutron sensor, electronic loop seal and rechargeable Li-ion battery. All these sensors are connected with monitoring system via two-layered network, i.e., via wired Ethernet and wireless network for security purposes. Due to [10] ships carrying RAM cargo are equipped with an automatic voyage monitoring system which transmits details of the vessel's position, speed and heading to the Report Center (Barrow, UK) every two hours. These transmissions are performed automatically and without any intervention of the crew. If message is not received at the allotted time the Emergency Response System would be activated. In [10] is stated: "It is probable that the transmission system would be based on, or similar to, the widely used INMARSAT C communication system which uses geo-stationary satellites positioned over the equator to receive and transmit the data." As an alternative, one can conjecture that Officers on Watch (OoW) and/or Master should monitor and control cargo holds through back-end info-communication system with the appropriate software architecture and interface similar to ARG-US system. In addition, they might be responsible for regular reporting to the Report Center. If we assume that VHF Data Exchange System (VDES) is used for this purpose, than the reports should be sent via Application Specific Message (ASM) 6 (dangerous cargo indication + following communication) to the land based controlreport center. The ASM 6 contains the information as: MMSI, flag, unit of quantity of dangerous cargo, code under which cargo is carried, BC class, IMDG class, and like [12]. Following communication should contain the data set on: temperature sensor, 3-axis digital accelerometer, gamma sensor, neutron sensor, electronic loop seal and Li-ion battery status. Within the context, it is important to underline that mandatory reporting from ships is usually encapsulated into ASM, while Maritime Service Portfolio (MSP) cover a number of Vessel Traffic Service (VTS) related and other services [3]. Additionally, possibilities of using Iridium GMDSS [13] should be further elaborated. Apart from the proposed model based on the assumptions, through further research work some efforts should be made to identify exact extraterrestrial communication channel(s) and method(s) of (automatic) reporting, used as a bidirectional link between ships carrying nuclear cargo and ground based (control) report center(s).

\section{CONCLUSION}

The paper proposes a model, at rather high level of abstraction, of communication between a ship carrying nuclear cargo and land based control center in sea transportation. The model is based on the experiences from Argonne ARG-US RFID projects. Conceiving and designing a model has been adopted to the PNLT ships performances and ship to shore and vice versa communication channels. After extensive web search, it has been concluded that online literature sources in this field are scarce. Further investigation should go in two directions: (i) exploring data transfer between sealed and tagged RAM drums and monitoring system on board ship, and (ii) exploring in more detail communications between the ship carrying nuclear cargo and (control) report center ashore. Due to the lack of available information, we can only assume which form of data exchange and which communication channels are used. We have conjectured that ASM 6 reporting method within VDES might be used, but it might be also INMARSAT C, Iridium GMDSS, or some other extraterrestrial communication mode for providing safety and security at sea while transporting nuclear cargo. However, this is to be elaborated in more detail in forthcoming research.

\section{REFERENCES}

[1] Argonne (n.d.). Continuous Unattended Monitoring of the Alpha Gamma Hot Cell Facility with ARG-US RFID System. Retrieved from: https://www.ne.anl.gov/pdfs/dis_AlphaGamBroch_v16. pdf (last access: 9th January 2021).

[2] ARG-US: The Watchful Guardian (26 March 2015). [Video]. Retrieved from: https://www.youtube.com/watch?v=b7Pr6KQ7WQQ (last access: 9th January 2021).

[3] Bauk S., A Review of NAVDAT and VDES as Upgrades of Maritime Communication Systems, in Advances in Maritime Navigation and Safety of Sea Transportation, eds. Adam Weintrit, Tomasz Neumann, The Nautical Institute, Gdynia, Poland, CRS Press, Taylor \& Francis Group, 2019, pp. 82-87.

[4] Bauk S., Dzankic R., Tracking radioactive materials in sea transportation via RFID technology, Proc. of the 8th Maritime Transport Conference, Barcelona, Spain, 17-18 September 2020, pp. 91-102.

[5] Brown A. A., Sea transport of irradiated nuclear fuel, plutonium and high-level radioactive wastes, Safe and Secure Transport and Storage of Radioactive Materials, 2015; https://doi.org/10.1016/B978-1-78242-309-6.000113.

[6] Chen et al., A Radiofrequency identification (RFID) temperature-monitoring system for extended maintenance of nuclear materials packaging, Proc. of 2009 ASME Pressure Vessels and Piping Division Conference, July 26-30, Prague, Czech Republic, doi:10.1115/PVP2009-77265.

[7] Chen K. et al., Development of the RFID system for nuclear materials management, Internet resource, Retrieved from: https://www.osti.gov/biblio/1015542development-rfid-system-nuclear-materialsmanagement (last access on: 9th January 2020).

[8] Craig B. et al., ARG-US Remote Area Modular Monitoring: Digital Cameras for Enhancing Safety and Security, INMM 59th Annual Meeting, July 22-26, 2018, Baltimore, Maryland USA, Retrieved from: https://rampac.energy.gov/docs/default- 
source/tracking/inmm59-craig_ramm.pdf (last access: 13th January 2020).

[9] Craig B., Anderson J., Lee H., Tsai H., Liu Y., Shuler J., Tracking and Monitoring Nuclear Material and Waste Packages by Using the ARG-US Radio Frequency Identification System, WM2011 Conference, March 7 11, 2011, Phoenix, AZ, Retrieved from: https://www.ne.anl.gov/pdfs/pclcm/68971.pdf (last access: 9th January 2021).

[10] Deere-Jones T., A review of aspects of the marine transport of radioactive materials - A report to Greenpeace International, Retrieved from: https://pdfslide.net/download/link/a-review-of-aspectsof-the-marine-transport-of-radioactive-review-ofaspects (last access: 14th January 2020).

[11] IAEA, Nuclear Power: The Road to a Carbon Free Future, Published: 8th January 2020, Retrieved from: https://www.iaea.org/ (last access: 9th January 2020).

[12] IALA, Application Specific messages - Dangerous Cargo Indication, Retrieved from: https://www.ialaaism.org/asm/dangerous-cargo-indication/ (last access: 12th January 2020).

[13] Iridium, Iridium GMDSS, Retrieved from: https://www.iridium.com/services/gmdss/ (last access: 14th January 2020).

[14] Janssens-Maenhout G. et al., Contributing to shipping container security: can passive sensors bring a solution?, Journal of Environmental Radioactivity, 101 (2010), pp. 95-105.

[15] Liu Y. Y. et al., ARG-US "Traveler" for Tracking and Monitoring Conveyances, INMM 59th Annual Meeting, July 22-26, 2018, Baltimore, Maryland USA, Retrieved from: https://rampac.energy.gov/docs/defaultsource/tracking/inmm59-liu_traveler.pdf (last access: 13th January 2020).

[16] Liu Y., Tsai H.C., Shuler J., Extending intervals for periodic leakage rate testing of radioactive material transportation packagings, Packaging, Transport, Storage \& Security of Radioactive Material, Vol. 22, No. 1, 2011, pp. 27-34.

[17] Liu Y.Y., Craig B., and Shuler J., ARG-US Remote Monitoring Systems for Enhancing Security of Radioactive Material, IAEA International Conference on the Security of Radioactive Material: The Way Forward for Prevention and Detection, Vienna, Austria, Dec. 3-7, 2018.

[18] Perovich S.M., Bauk S., Determination of Plutonium Temperature by Using The Special Trans Function Theory, Nuclear Technology \& Radiation Protection Journal, Vol. 25, No. 3, 2010, pp. 164-170.

[19] PNTL UK (n.d.). PNTL Ships [Video]. Retrieved from: https://www.pntl.co.uk/our-fleet/pntl-ships/ (last access: 9th January 2021).

[20] PNTL, Contingency Procedures, Retrieved from: https://www.pntl.co.uk/our-fleet/contigencyprocedures/ (last access: 12th January 2020).

[21] PNTL, PNTL Ship Animation, Retrieved from: https://www.pntl.co.uk/our-fleet/pntl-ship-animation/ (last access: 12th January 2020).

[22] PNTL, PNTL Ship Tour, Retrieved from: https://www.pntl.co.uk/our-fleet/pntl-ship-tour/ (last access: 12th January 2020).

[23] Roberts C. M., Radio frequency identification (RFID), Computers \& Security, 25 (2006), pp. 18-26.

[24] Tsai H. C., Chen K., Liu Y. Y. \& Shuler J. M., Demonstration (DEMO) of radiofrequency identification (RFID) system for tracking and monitoring of nuclear materials, Packaging, Transport, Storage \& Security of Radioactive Material, 21(2), 2010, pp. 91-102.

[25] Tsai H.C. et al., Applying RFID technology in nuclear materials management, Packaging, Transport, Storage \& Security of Radioactive Material, Vol. 19, No. 1, 2008, pp. 41-46.

[26] Watanabe F. et al., Study of Tracking System for Radioactive Material Transport, 14th International Symposium on the Packaging and Transportation of Radioactive Materials (PATRAM 2004), Berlin, Germany, September 20-24, 2004, Retrieved from: https://www.osti.gov/etdeweb/servlets/purl/20773349 (last access: 13th January 2020).

[27] Wonham J. et al., Marine transportation of irradiated nuclear fuel, plutonium and radioactive wastes: the continuing debate on regulatory measures, Marine Policy, 24(2000), pp. 287-299.

[28] World Nuclear Transport Institute (WNTI), Fact sheet: Quick facts on the transport of Nuclear Fuel Cycle Transport, Internet resource, Retrieved from: https://www.wnti.co.uk/media/31603/FS6_EN_MAR13_ V2.pdf (last access on: 9th January 2020). 